\title{
Suspected Johne's Disease in a Herd of Dairy Cattle: a Case Report
}

\author{
${ }^{1,2}$ Faez Firdaus Jesse Abdullah, ${ }^{1,3}$ Lawan Adamu, ${ }^{1}$ Yee Jia Yin, \\ ${ }^{1}$ Abdinasir Yusuf Osman, ${ }^{1,2}$ Abdul Wahid Haron, and ${ }^{1}$ Abdul Aziz Saharee \\ ${ }^{I}$ Department of Veterinary Clinical Studies, Faculty of Veterinary Medicine, Universiti Putra Malaysia, 43400 \\ Serdang, Selangor, Malaysia, \\ ${ }^{2}$ Research Centre for Ruminant Disease, Universiti Putra Malaysia, 43400 Serdang, Selangor, Malaysia, \\ ${ }^{3}$ Department of Veterinary Medicine, Faculty of Veterinary Medicine, University of Maiduguri, PMB1069, \\ Borno State, Nigeria
}

\begin{abstract}
Four adult Friesian cross cows were experiencing intermittent diarrhea and chronic weight loss in a dairy farm in Dengkil, Negeri Sembilan. They were managed semi-intensively with pelleted diet and kept with a herd of 80 dairy cattles. One of the cattle, Kuning, experienced drop in milk yield from 10L/day to $2 \mathrm{~L} / \mathrm{day}$. Physical examination revealed a poor body condition score of $2 / 5$ in all 4 cattles, although they have good appetite. The differential diagnoses were Johne's disease, fascioliasis, chronic salmonellosis and coccidiosis. Laboratory diagnosis of Ziehl- Neelsen stained faecal smears from all 4 cattles revealed presence of acid fast bacteria. Haematology and serum biochemistry results of all 4 cattles shown lymphocytosis and hyperglobulinemia. Based on the compatible clinical signs, haematology and serum biochemistry results, presence of acid fast bacteria, diagnosis of suspected Johne's disease is made. A herd screening revealed 9 out of 30 cattles had acid fast stained bacteria in the faeces.
\end{abstract}

Keywords: Johne's disease, dairy cattle, acid fast bacteria

\section{Introduction}

Johne's disease is caused by Mycobacterium avium subsp. Paratuberculosis (MAP). It was first observed by Johne and Frothingham in 1895[1]. It is an acid fast, short rod and obligates bacteria. It means that it cannot replicate outside the animal host. This disease is found in all ruminants and has a global distribution. It was first recognized in cattle, then in sheep, and later in goats [1].

This disease is a chronic wasting disease, where the animal affected often presented with poor body condition score, however often with good appetite [2]. It affects the small intestine of all ruminants, causing persistent diarrhoea that is not responsive to treatment [2]. The clinical signs of Johne's disease in cattle are easily recognized, they are pipestream diarrhea, chronic weight loss, and edema due to hypoproteinemia caused by protein-losing enteropathy [3].

The transmission of MAP is via faecal and oral routes. Calf usually infected when they ingest infected milk from infected dam [4]. These bacteria then incubate in the small intestine and the cattle only exhibit clinical signs at 3-5 years of age [4]. Its long incubation period, along with the fastidious growth requirements of MAP in vitro and blunted humoral immune response has made diagnosis of Johne's disease a challenge [3].

As this disease causes chronic weight loss and reduced milk yield, it causes severe economical losses to the dairy farmers. In U.S., the national institute for animal agriculture estimated that Johne's disease causes a loss of US dollars 200 to 250 million per year [4].

\section{Case Report}

On 18th March 2013, a farm visit at Dengkil, Negeri Sembilan was made. The farm has 80 dariy cattles. They were all managed semi-intensively, with pelleted diet. Owner complained that there were 4 cattles, Kuning, Dechek, Kutu and Baghei were having diarrhea 2 weeks ago and they were experiencing continual weight loss. One of the cattle, Kuning's milk yield reduced from its usual 10L/day to $2 \mathrm{~L} /$ day. All these 4 cattles were all adult female Friesian cross.

The physical examination revealed that all 4 cattles have poor body condition score of 3 out of 5 . Their temperature, heart rate and respiration rate were all within normal range. Their mammary glands were all normal, without any signs of mastitis. The hydration status of all the cattle was normal except Kuning who had $8 \%$ of dehydration rate. Upon rectal palpation, Kuning had soft watery, light brown faeces. Mild corrugation of the rectal wall was felt. 


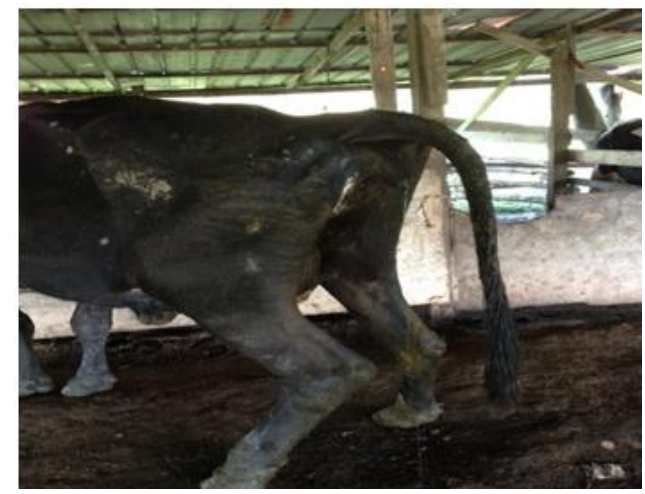

Figure 1: Kuning, one of the cattle affected with diarrhea and chronic weight loss.

Therefore the problems list, differential diagnosis and diagnostic workup at that moment were as illustrated in table 1 below:

\begin{tabular}{|c|c|c|}
\hline Problem lists & Differential diagnosis & Diagnostic workup \\
\hline Chronic weight & Johne's $\quad$ disease $\quad$ (Mycobacterium & Haematology \\
\hline & Paratuberculosis) & biochemistry \\
\hline Persistent & Liver fluke infestation (Fascioliasis) & Faecal bacterial culture, \\
\hline diarrhea & Chronic salmonella & Ziehl-Neelsen stain, \\
\hline $8 \%$ dehydration & Coccidiosis & sedimentation \\
\hline $\begin{array}{l}\text { Reduced milk } \\
\text { yield }\end{array}$ & & floatation \\
\hline
\end{tabular}

Several diagnostic work out were performed. Blood sample were collected via jugular venipuncture and faecal sample was collected manually via the rectum from all the 4 cattles. For the faecal sample, ZiehlNeelsen stain was done on faecal smear to examine for acid-fast bacteria. Faecal bacterial culture was also done to determine if salmonella could be the cause of diarrhea. Besides, sedimentation and simple floatation were performed to examine for any liver fluke ova and coccidia oocyts respectively. For the blood sample, it was sent to clinical pathology laboratory for haematology and serum biochemistry evaluation.

While waiting for the laboratory diagnosis, Kuning with the worst condition was treated. The $8 \%$ dehydration rate was corrected by intravenous administration of $0.9 \%$ sodium chloride fluid. Oxytetracyline $200 \mathrm{mg} / \mathrm{mL}, 20 \mathrm{mg} / \mathrm{kg}$ was administered intramuscularly and ivermectin was administered subcutaneously at a dose rate of $1 \mathrm{~mL} / 50 \mathrm{~kg}$.

Ziehl-Neeson faecal smear acid fast stain revealed presence of acid fast bacteria that stained bright red in all the 4 cattles. In Kuning who had watery faeces, a few clusters of acid fast stained short rods were observed under 100x magnification of light microscope; while the other 3 cattles with pasty faeces had a few acid-fast stained bacteria observed. These acid fast bacteria are likely to be Mycobacterium Paratuberculosis (MAP) in this case report.

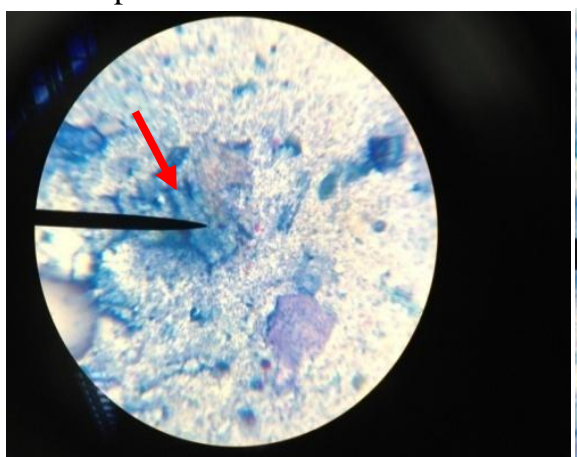

A

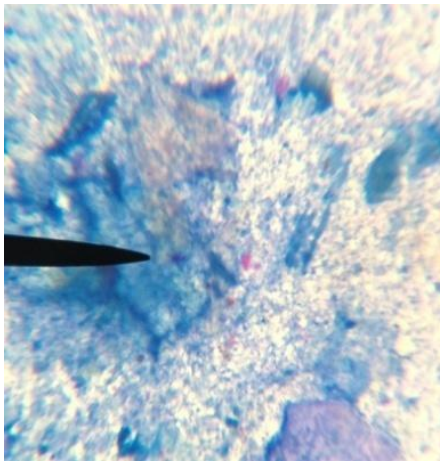

B

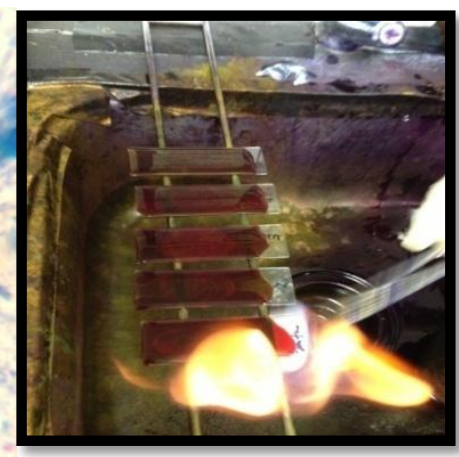

C

Figure 2: $[\mathrm{A}]$ Kuning's faecal smear revealed a cluster of acid fast stained bacteria observed under light microscope of x100 magnification; [B] Only a few acid fast stained bacteria were observed in the other 3 cattle; [C] Acid fast bacteria will stained bright red. 
Bacterial culture revealed that all 4 cattles have Escherichia coli and Bacillus $s p$ of $4+$ growth. Both E.coli and Bacillus sp are normal flora of the gastrointestinal tract of cattle, and a 4+ growth may be due to overpopulation of normal flora due to immunosuppression from other underlying problem. Faecal sedimentation revealed occasional paramphistoma ova, which are rumen flukes in 3 of the cattles. The rumen flukes are not pathogenic and are not likely to be the cause of persistent diarrhoea and chronic weight loss. Simple floatation of all cattle's faecal samples was negative for oocyts. Generally, haematology and serum biochemistry results of all the cattles showed lymphocytosis and hyperglobulinemia, which are consistent with chronic infection.

As no fasciola ova were seen under light microscope using sedimentation method, therefore liver fluke infestation was ruled out. Besides, Gamma-glutamyl transpeptidase (GGT) liver parameters were all within the normal range. Chronic salmonellosis was ruled out as there was no salmonella growth on all the faeces cultured. Coccidiosis was ruled out as no coccidian oocyts were found in simple floatation method.

A revisit was done to collect 30 other clinically normal dairy cattle faecal samples and Ziehl- Neelson acid fast stain was carried out. 9 out of 30 cattles' faecal sample were positive for acid fast bacteria; however, they were present in a few small clusters.

To confirm the diagnosis of Johne's disease, bacterial culture of mycobacterium Paratuberculosis is the gold standard. However, this method may take up to 4 months. Therefore, based on the history, compatible clinical signs, physical examinations findings and the presence of positive acid fast bacteria in faeces, diagnosis of suspected Johne's disease was made.

\section{Pathogenesis:}

\section{Discussion}

MAP is transmitted by the fecal-oral route. Calf ingested infected milk with MAP bacteria from the dam, and then the MAP is taken up by macrophage in payer's patches in terminal ileum. The bacteria then multiply intracellularly in the small intestine. As MAP replicate intracellularly slowly, it is difficult for immune response to eradicate the bacteria and therefore this leads to a low humoral response [5].

Early lesions occur in the walls of the small intestine and the draining mesenteric lymph nodes, and infection is often confined to these sites at this stage. As the disease progresses, gross lesions occur in the ileum, jejunum, terminal small intestine, caecum and colon, and in the mesenteric lymph nodes [1]. This granulomatous lesion causes protein leakage and malabsorption, in a long run, these leads to chronic weight loss. The MAP bacteria are found to be present in the lesions and, terminally, present throughout the body [1].

Diarrhea in Johne's disease is slowly progressive, starting with intermittent diarrhoea, and then becoming progressively more severe until it is constantly present [6]. Subclinical carriers excrete variable numbers of M. Paratuberculosis in the faeces while in most cases, larger numbers of organisms are excreted as clinical disease develops [1].

\section{Diagnosis}

The diagnosis of Paratuberculosis is pretty challenging, especially in subclinically infected cattle. This is due to limiting shedding of bacteria in subclinically infected cattle and due to the lack of accurate diagnostic tests [7].

Faecal culture with Herrold's Egg Yolk medium is the gold standard for diagnosing Johne's disease. However, as mentioned earlier, the culture takes long duration from 8 to 16 weeks [3]. Besides, as subclinically infected animals may shed minimally, in some cases not shedding the bacteria at all, faecal culture method is less useful in detecting subclinically infected animal. Kol. J.L, (2011) stated that although faecal culture is seen as the gold standard for the diagnosis of Paratuberculosis, repeated testing is necessary, and a combination with serology method is recommended.

Besides, Ziehl-Neelsen fecal smear stain can be used to make presumptive diagnosis, when clumps of three or more acid-fast bacilli are found [1]. The disadvantage of Ziehl-Neelsen fecal smear stain is it does not differentiate among other mycobacterium species [1]. In our case, cattles with no diarrhoea has minimum to none acid fast bacteria observed under microscope, while Kuning who had the most severe diarrhoea, had the highest amount of acid fast bacteria observed.

The ELISA technique is the most commonly used laboratory test for the detection of specific antibodies against MAP in serum today [9]. It is more cost effective and rapid compared to fecal culture [3]. The sensitivity and specificity of ELISA vary in a wide range, depending on the test kit and the gold standard used.

Sensitivity varies between $7 \%$ and $94 \%$, and specificity from $41 \%$ to $100 \%$ [9]. Due to its high throughput, this method is commonly used in estimating the prevalence of MAP infection in a herd [10]. However, detectable antibodies are usually not produced until late in infection and after fecal shedding has begun [8]. Besides, Stable J.R., (1998) also stated that serology is less useful in detecting subclinically infected animal as animal animals do not develop an antibody response until the clinical stages of disease. 
Polymerase Chain Reaction (PCR) can also be used for the detection of MAP in faeces, tissue, blood and milk samples [11]. It is rapid and accurate, especially in real-time PCR methods which allow estimation of amount of MAP shedding in feces, with good correlation with culture methods [13]. However, it might be an economic concern to farmers. Therefore, most of the time, clinical diagnosis is made based on compatible clinical signs, physical examination findings and positive for acid fast stain.

\section{Disease control and eradication}

Till date, there is no effective treatment for Johne's disease [3]. To control the disease, as it is a reportable disease to Department of Veterinary Services (DVS), suspected or confirmed cases should be reported to DVS so that prompt herd screening using ELISA or PCR can be done. If the cattle are confirmed positive, test and cull policy with compensation is practiced. The carcasses should be examined for lesion to confirm the diagnosis [14].

However, due to the difficulty in detecting carrier animals as mentioned earlier, eradication of Johne's disease from a herd is unlikely to be successful [14]. Therefore in infected herd with Johne's disease, test and manage policy can be practiced [1]. One of the management method is to separate the calves from cows at birth, as well as spatial separation of calf-raising areas from adult animals [1]. Separate equipment should also be used for handling feed and scraping or hauling manure. Besides, suspected infected animal should not be breed [1].

The prevalence of Johne's disease in Malaysia in 2010 from VRI using complement fixation test (CFT) was $0.22 \%$. There were 123 cases positive out of 56008 cases, however mind that complement fixation test only detects antibody which will only be detected in clinical stage of disease. Therefore, this prevalence study does not include the subclinically infected cattles. In nationwide, breeders should conduct annual whole-herd screening by faecal culture or PCR on individual cattle to establish disease free status [1].

\section{Client education}

In cases of Johne's disease, farmer should be advised to isolate cattle tested positive, and ensure their faeces do not contaminate other places as transmission is via faecal-oral route. As MAP can be transmitted via infected milk, calf of the positive dam should be foster to disease free cows [1]. Test and cull policy should be practice by the farmers as Johne's disease causes economical losses to the farmers. Other than that, suspected and positive diseased cattle should be reported to the Department of Veterinary Services (DVS), to aid in herd screening. In future if depopulation is practiced, farmer should buy cattle from MAP disease free herd. Or the best way is to rear their heifer replacements [1].

\section{Conclusion}

In conclusion, Johne's disease is an economical important disease in dairy industry in Malaysia; it should be a concern issue in diary industry. Secondly, definite diagnosis of Johne's disease via PCR should be done as early as possible to eradicate the disease from the herd. In disease control and eradication nationwide, DVS plays an important role and close collaboration between DVS and farmer will ensure an effective control of Johne's disease in the country. Lastly, closed herd system is the key to prevent this disease from entering the farms after eradication is successfully accomplished.

\section{Acknowledgement}

The authors wish to acknowledge En Nazim Razali Kanini, En Mohd Jefri, University Veterinary Hospital (UVH), and Faculty of Veterinary Medicine Universiti Putra Malaysia for their technical assistance.

\section{References}

[1] Paratuberculosis Chapter 2.1.11, OIE Terrestial Manual 2008, page 277.

[2] Harris, N. B., and R. G. Barletta, 2001, Mycobacterium avium subsp. Paratuberculosis in Veterinary Medicine. Clin. Microbiol. Rev. 14: $489-512$

[3] Sweeney R.W., Collins M.T., Koets A.P., McGuirk S.M., and Roussel A.J., Paratuberculosis (Johne's Disease) in Cattle and Other Susceptible Species, ACVIM Consensus Statement, 2012, J Vet Intern Med;26:1239-1250.

[4] Franklyn Garry, DVM, MS, ACVIM, Control of Paratuberculosis in Dairy Herds, 2011, Vet Clin Food Anim 27, 599-607, doi:10.1016/j.cvfa.2011.07.006

[5] Collins M.T., Johne's disease, An Issue of Veterinary Clinics: Food Animal Practice, 2011, Elsevier Health Sciences.

[6] Gilmour N.J.L., Mycobacterium Paratuberculosis. In: Handbuch der Bakteriellen Infektionen bei Tieren, Blobel H. \& Schliesser T., 1954,eds. Gustav Fischer Verlag, Jena, Germany, 281-313.

[7] Collins, M.T., Diagnosis of Paratuberculosis, in the Veterinary Clinics of North America: Food Animal Practice, R.W. Sweeney, Editor. Vol. 12(2). 1996, W. B. Saunders Company: Philadelphia. p. 357-71.

[8] Sweeney RW, Whitlock RH, McAdams S, et al. Longitudinal study of ELISA seroreactivity to Mycobacterium avium subsp. Paratuberculosis in infected cattle and culture-negative herd mates. J Vet Diagn Invest 2006; 18: 2-6.

[9] Nielsen SS, Toft N. Ante mortem diagnosis of Paratuberculosis: A review of accuracies of ELISA, interferon-gamma assay and faecal culture techniques. Vet Microbiol 2008; 129: 217-235. 
[10] Paratuberculosis, IOWA State University, The centre for food security and public health, 2007.

[11] Bölske, G., Hertnek, D., Diagnosis of Paratuberculosis by PCR. In: Paratuberculosis: Organism, Disease, Control, 2010, CAB International, Oxfordshire, UK, pp267-283.

[12] Khol JL, Kralik P, Slana I, Beran V, Aurich C, Baumgartner W, Pavlik, Consecutive excretion of Mycobacterium avium subspecies Paratuberculosis in semen of a breeding bull compared to the distribution in feces, tissue and blood by IS900 and F57 quantitative real-time PCR and culture examinations, 2010 Oct, J Vet Med Sci.;72(10):1283-8.

[13] Aly SS, Mangold BL, Whitlock RH, et al. Correlation between Herrold's egg yolk medium culture and real-time quantitative polymerase chain reaction results for Mycobacterium avium subspecies Paratuberculosis in pooled fecal and environmental samples. 2010, J Vet Diagn Invest; 22:677-683.

[14] Chunu Mainali, Alberta Agriculture and Rural Development, 2012, Johne's disease, Agri-fact: Practical information for Alberta's agriculture industry 